\title{
Integration \& Implication of Machine Learning: Barriers to Aid Environmental Monitoring \& Management
}

\author{
Mohammad Ali1, Mirza Md. Tasnim Mukarram¹, Md. Arif Chowdhury ${ }^{2 *}$, \\ Shahnam Karin ${ }^{3}$, Alimun Nessa Faruq ${ }^{4}$ \\ ${ }^{1}$ Military Institute of Science and Technology, Mirpur Cantonment, Dhaka, Bangladesh \\ ${ }^{2}$ Department of Climate and Disaster Management, Jashore Universiy of Science and Technology, Jashore, Bangladesh \\ ${ }^{3}$ The United Nations Children's Fund (UNICEF), Cox's Bazar, Bangladesh \\ ${ }^{4}$ Haor Flood Management and Livelihood Improvement Project, Local Government Engineering Department, Dhaka, Bangladesh \\ Email: *arifchowdhury065@gmail.com
}

How to cite this paper: Ali, M., Mukarram, M.Md.T., Chowdhury, Md.A., Karin, S. and Faruq, A.N. (2021) Integration \& Implication of Machine Learning: Barriers to Aid Environmental Monitoring \& Management. Open Access Library Journal, 8: e7468.

https://doi.org/10.4236/oalib.1107468

Received: April 28, 2021

Accepted: June 20, 2021

Published: June 23, 2021

Copyright $\odot 2021$ by author(s) and Open Access Library Inc.

This work is licensed under the Creative Commons Attribution International License (CC BY 4.0).

http://creativecommons.org/licenses/by/4.0/

\section{(c) (i) Open Access}

\begin{abstract}
With the development of artificial intelligence and other associated models like machine learning, data science, industrial internet of things etc. it has become a significant challenge for the majority of the practitioners and researchers in field of environmental monitoring and management to keep pace with. Though many international universities in developed countries are making significant contributions to this field, the obstacle remained constant in Bangladesh. Focusing the background, this study is conducted to understand the challenges to integrate and implication of machine learning regarding environmental monitoring and management in Bangladesh. In this study, 20 surveys and 5 In-depth Interviews were conducted with practitioners from eight top institutes those are working on environmental monitoring and management related issues in government, non-government and academia sectors of Bangladesh. Findings revealed that in case of absence of reliable resources on an average intensity of participants is 9.15, where the Intensity of participants in favor of absence of less exposure of research upshots (average is 8.50). Also, lack of sharing information and absence of available funding are identified as major obstacles. This study may help stakeholders to take proper initiatives to encourage researchers and practitioners regarding utilization of machine learning in Bangladesh.
\end{abstract}

\section{Subject Areas}

Earth and Environmental Sciences 


\section{Keywords}

Machine Learning, Environmental Monitoring, Process-Based Modelling, Practitioners, Decision-Aid Tools

\section{Introduction}

"Machine Learning" (ML) algorithms have abetted in decoding multitude of domain-specific problems in various branches of engineering including to monitoring natural disasters [1], weather forecasting, and many more. Augmented energy consumption and environmental impact on the human has become one of the most burning global issues [2]. The algorithms are not required to be unambiguously programmed and are incredibly effective at learning, and making predictions from archetypes in data [3]. They can be used at predicting complicated responses from a plethora of data types. ML models are skilled at predicting nuanced and nonlinear relationships from complex, high-resolution datasets [4]. With the progress and development of our capacity to scrutinize the environment, ML models' role in the environmental monitoring and management sectors is also augmenting. There is an extremely positive correlation between the boost of ML algorithms and the Industrial Internet of Things (IIoT) [5]. The need for human interaction during data collection and operations are reducing with the development of IIoTs. Though the breakthrough of artificial intelligence and data science is intriguing and boosting quite fast the application of ML models to explore environmental datasets and thrive predictive decision support contraptions remains a significant obstacle for many researchers and practitioners working in the environmental sectors. Some of the significant issues regarding the use of ML models include data-based challenges, atrocious accessibility to computational tools and confined knowledge exchange between environmental engineers, scientists, data scientists, and policymakers [6]. Actually, no single indicator can aptly supervise the human impact on the environment [7]. Basically, all the types of indicators are taken in to consideration based on the environmental aspects [8]. In order to make observational data more available to the global community new modelling approaches are being built to augment the availability [9]. The indicators of environmental and sustainable development comprise of clear and timely signals about specific environmental process [10].

In many regions, massive and rapid urbanization is happening and as a result plethora of construction works are being observed [11]. During early stages of construction work it becomes very difficult to assess environmental impacts as problems arises to cope up with the eccentricity of the detailed design information's [12]. Augmented environmental burdens and energy consumptions are the upshots of updated built buildings and structures like as: $\mathrm{CO}_{2}$ emissions in the urban areas [13]. It is not plausible to obtain parameters of any sort of de- 
tailed designs for construction works or monitoring any environmental parameters as well during the inception stage. So, design related information's is not fully obtained and this negatively impacts the environmental assessment methods for life-cycle assessment [12]. Currently, one of the most pressing and burning issues of the globe is climate change and the challenge for the researchers and practitioners are developing sustainable energy sources without harming the natural environment. The importance of holistic approaches is immense in this.

However, it is also very important to anticipate and make apt assumptions about environmental contaminants. Integration of ML can assist to obtain more precise forecast information's about environmental parameters. As the technologies are upgrading so the researchers and practitioners with conventional systems thinking and methodological approaches will be facing myriad of challenges in the coming centuries and in the current trend as well. Machine learning can transcend technologies and integrate multiple environmental parameters simultaneously to address environmental monitoring aptly. Holistic approaches integrating machine learning can easily reduce pollution, waste, energy, and water consumption associated with environment and health. The population of the world is augmenting day by day and, it is creating a lot of pressure on resources consumption, pollution and waste as well [14]. For the evolution of environmental monitoring and management system the grand challenges must be addressed properly. Without any doubt this is unquestionably an ambitious vision and is imperative for the future development of environment researchers and practitioners.

Machine learning practice is increasing in the current world, while analyzing advance computational issues at large and extraordinary scales [3] [15]. Also, ML models are suitable to assume nuanced and nonlinear relationships analyzing high resolution datasets [16] [17]. Following the advances of using ML models, [18] and [19] summarized that ML models may enhance natural resources management through unfolding environmental data and showing possible modeling capability. Although ML model practices are increasing all over the world, researchers and practitioners in Bangladesh are becoming familiar to these also. Besides, capacity of faculties, practitioners from government and non-government sectors, young researchers are developing, where new technology based analysis and advanced level study are getting priority day by day. Although researchers and academicians from environment are trying to acquire the skill to address environmental monitoring and management related issues, there are still various forms of barriers to ensure sustainable approach. There are some available research, which show expertize and interest of researchers on ML related issues in South Asia [20] [21] [22] and Bangladesh [23] [24]. Following the background, this study is conducted to understand the obstacles to aid environmental monitoring and management regarding integration and implication of machine learning in Bangladesh. This study will help people identify the actual problems 
associated with machine learning in environmental engineering and management. It will also allow the practitioners and policymakers to use practical decision-making tools to combat and solve the issues.

\section{Methodology}

This research is conducted following a mixed method approach e.g. quantitative and qualitative approach. Here, Key Informant Interviews and In Depth Interviews were done as quantitative and qualitative approach, respectively.

\subsection{Questionnaire Formulation}

In order to identify crucial factors which are working as obstacles in the field of implementing ML models in environmental sectors, we conducted a reconnaissance survey with some of the stakeholders in Bangladesh. During this reconnaissance survey, 5 experts and 5 non-experts on ML were participated from government, non-government, and academic sectors. Besides, an extensive literature review was done to find out the important issues to incorporate as the existing obstacles in the questionnaire.

\subsection{Sample Preparation}

This study was designed based on the perception of stakeholder those are working on different aspects of environmental management and monitoring but have not expert level experience regarding machine learning in Bangladesh. Among the different type's institutes in Bangladesh, institutes were selected purposively. After identifying 20 institutes including Government Organizations (GOs), university, and Non-Government Organizations (NGOs) related to environmental subject, list of stakeholders was prepared. Then, an online questionnaire form was sent to all of the stakeholders with a consent form including in details of ethical consideration of this study. Among them, a total number of 20 stakeholders and practitioners in the field of environmental (monitoring, management, science, engineering and policy-making) participated in this survey (Table 1). Here, a structured questionnaire was used to conduct this survey. Also, to understand the fact in details following the objectives of this study, 5 In Depth Interviews (IDIs) were conducted using zoom platform. Besides, the resource persons were selected based on their experiences with ML models and practitioners who have never used ML models and have little knowledge about ML models, and facing obstacle to be an expert on this. Background information of the respondents is given in Table 2.

\subsection{Data Collection and Analysis}

A total of 20 KIIs were conducted with key informant as presented in Table 1 and Table 2. All of the respondents answered the questions from 1 to 10 value, where $1=$ less agree and $10=$ fully agree, and 2 to 9 represents the level of statement on this scale. After that, all of the data was checked twice to ensure the 
Table 1. Number of respondents in selected institutes in Bangladesh.

\begin{tabular}{clc}
\hline \multicolumn{1}{c}{ Types of institutes } & \multicolumn{1}{c}{ Name of the institutes } & Number of KIIs \\
\hline & Bangladesh University of Engineering and Technology (BUET) & 5 \\
& Ahsanullah University of Science and Technology (AUST) & 3 \\
Academic/University & Military Institute of Science and Technology (MIST) & 2 \\
& Chittagong University of Engineering and Technology (CUET) & 3 \\
& Khulna University of Engineering and Technology (KUET) & 1 \\
\hline \multirow{2}{*}{ GO } & Local Government Engineering Department (LGED) & 2 \\
\hline & City Corporation (CC) & 3 \\
\hline NGO & International Center for Climate Change and Development (ICCCAD) & 20 \\
\hline
\end{tabular}

Table 2. Background information of the respondents.

\begin{tabular}{|c|c|c|c|c|c|}
\hline SI. & Gender & Age (Years) & Designation & Years of Experience & Institutions \\
\hline 1 & Male & 42 & Assistant. Professor & 7 & \multirow{3}{*}{ AUST } \\
\hline 2 & Male & 49 & Professor & 17 & \\
\hline 3 & Male & 52 & Professor & 19 & \\
\hline 4 & Male & 48 & Professor & 18 & \multirow{5}{*}{ BUET } \\
\hline 5 & Male & 52 & Professor & 18 & \\
\hline 6 & Male & 51 & Professor & 18 & \\
\hline 7 & Female & 55 & Professor & 20 & \\
\hline 8 & Male & 52 & Professor & 23 & \\
\hline 9 & Male & 51 & Project Director & 6 & $\mathrm{CC}$ \\
\hline 10 & Male & 45 & Professor & 15 & \multirow{3}{*}{ CUET } \\
\hline 11 & Male & 48 & Professor & 17 & \\
\hline 12 & Male & 55 & Professor & 17 & \\
\hline 13 & Male & 29 & Researcher & 2 & \multirow{3}{*}{ ICCCAD } \\
\hline 14 & Male & 36 & Researcher & 4 & \\
\hline 15 & Female & 30 & Researcher & 3 & \\
\hline 16 & Male & 39 & Associate Professor & 11 & KUET \\
\hline 17 & Male & 51 & Project Director & 17 & \multirow{2}{*}{ LGED } \\
\hline 18 & Male & 52 & Project Director & 18 & \\
\hline 19 & Male & 48 & Professor & 12 & \multirow{2}{*}{ MIST } \\
\hline 20 & Male & 29 & Lecturer & 3 & \\
\hline
\end{tabular}

Here, AUST $=$ Ahsanullah University of Science and Technology, BUET $=$ Bangladesh University of Engineering and Technology, CC = City Corporation, CUET = Chittagong University of Engineering and Technology, ICCCAD = International Center for Climate Change and Development, KUET $=$ Khulna University of Engineering and Technology, LGED = Local Government Engineering Department, MIST = Military Institute of Science and Technology. 
correct form of entry and Statistical Package for the Social Sciences (SPSS) 2020 software was used to analyze the data to fulfill the objectives. The list of questions asked to the participants (a scale of 10 was selected) and answered as numeric entries between 1 and 10 .

\section{Results and Discussion}

Based on the findings from numerical analysis and perception of the key informants, all of the issues e.g. Lack of available resources, Lack of information exchange, Less exposure to research upshots, Lack of funding, Lack of interest in machine learning, Usage of old conventional techniques, and Difficulty to adapt with machine learning are presented in this section.

\subsection{Lack of Available Resources}

The value of mean and the peak of the curve shows that most people are facing obstacles due to lack of appropriate resources (Figure 1(a)). In case of absence of reliable resources on an average intensity of participants is 9.15, when the number of observation is 20 . Also, the mean value is 9.15 , and the standard deviation is also significantly less, which is. 933. Besides, working experience as a factor of determining the connection with lack of resources, where 75th percentile value or the upper quartile of all the boxes are above 9 and the maximum value is 10 . The majority of the participants are facing challenges due to lack of

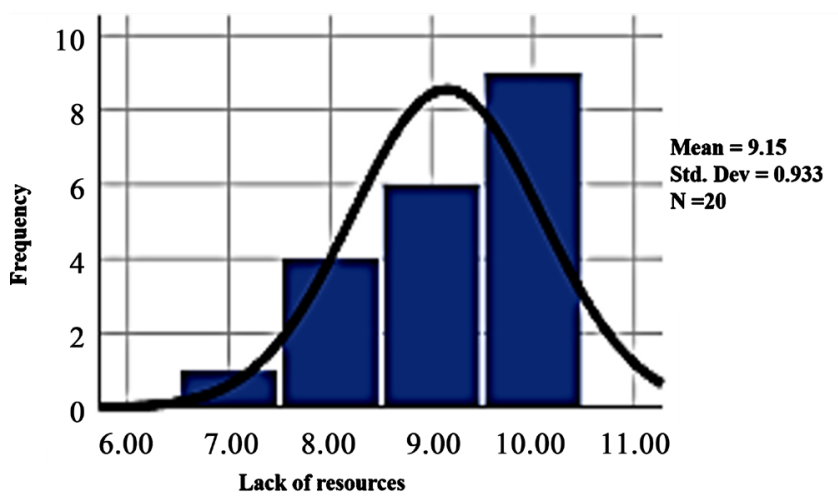

(a)

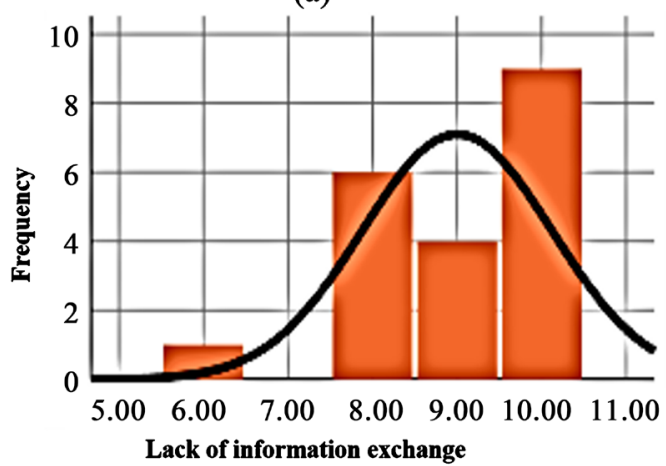

(b)

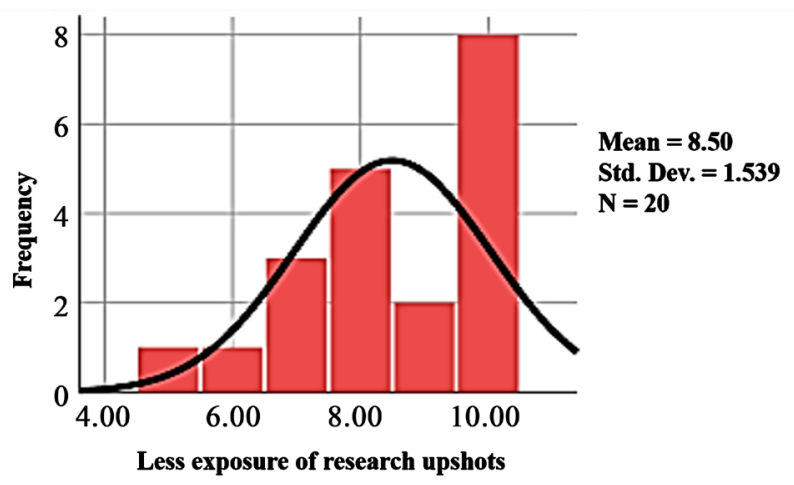

(c)

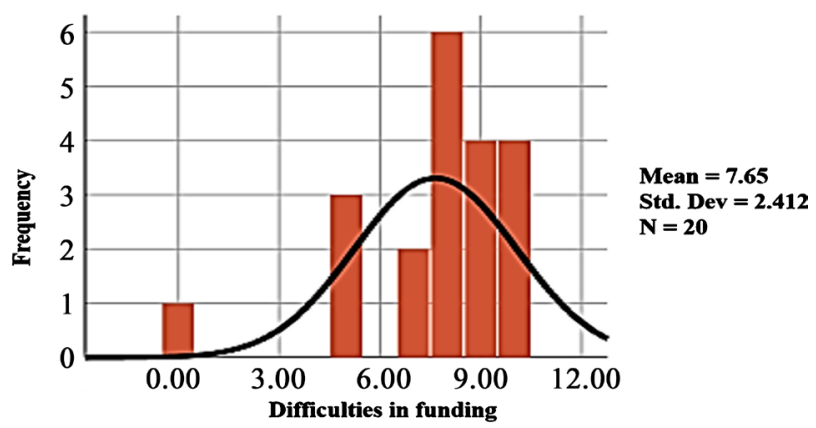

(d)

Figure 1. Perception of respondents on (a) lack of resources; (b) lack of information exchange; (c) less exposure of research upshots; and (d) difficulties in funding. 
proper resources and from the simple box plot diagram it can be clearly estimated and assumed that all the participating institutions depicts the upper quartile or the 75 th quartile is above 8.00 out of scale 10.00 . More specifically the participants from BUET and MIST strongly mentioned lack of machine learning relevant resources is a prime fact behind halting researchers and practitioners to implement machine learning in the environmental management field (Figure 2(a)).

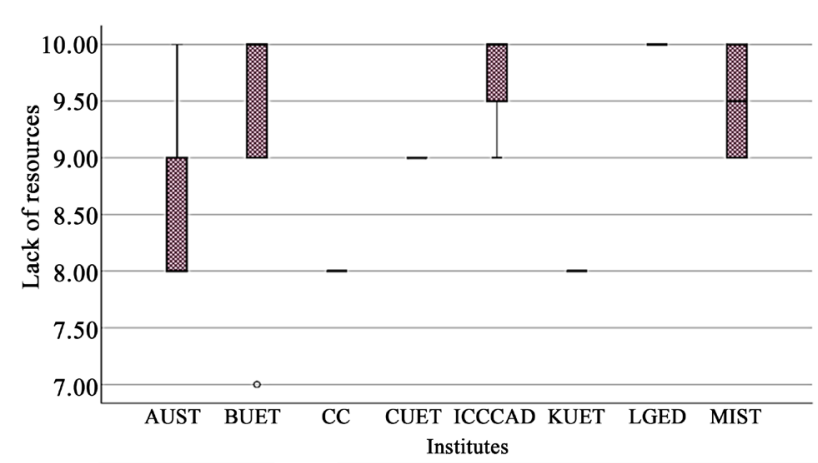

(a)

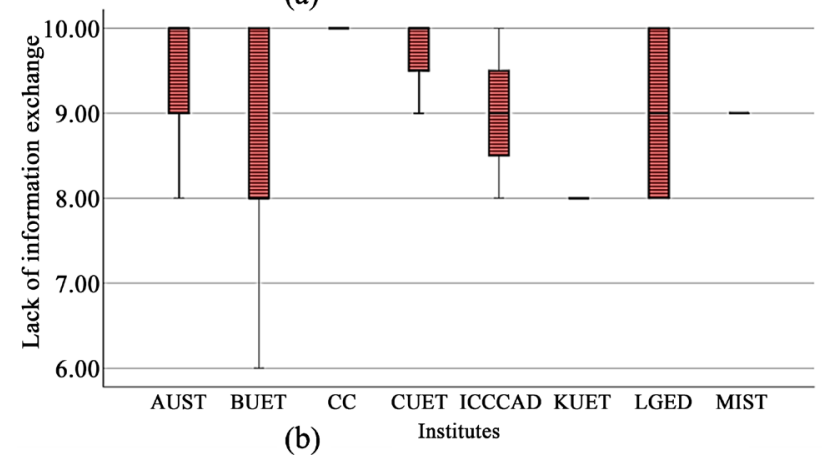

Figure 2. Institute wise scoring based on (a) lack of resources; (b) lack of information exchange; (c) lack of exposure of research upshots; (d) difficulties with funding

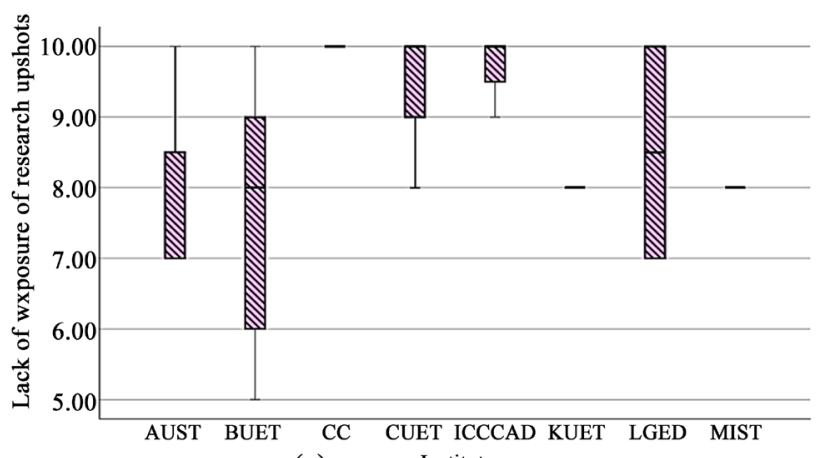

(c)

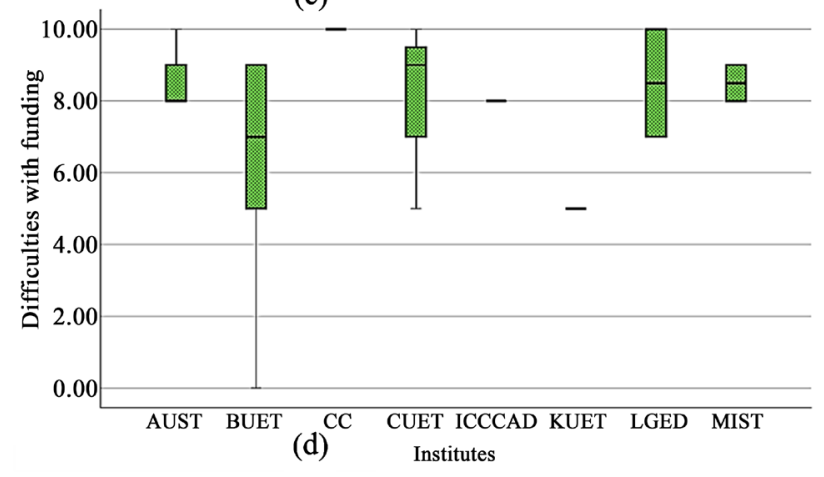

Furthermore, hence it can be said that the result of our assumption is positive. Besides, from the qualitative findings, it is observed that, the practitioners who participated expressed their consensus that ML models are definitely excellent sources of process-based modelling and can act as a great tool for aiding in decision-making, but the resources available are quite vague and inscrutable. As a result, it has become increasingly difficult to use them in the practical decision-making process for people working on environmental sectors.

\subsection{Lack of Information Exchange}

Researchers and other practitioners often consider ML models as "black boxes" as their patterns and learned relationships are not similar and not interpretable as classical statistical models and differential equations [25]. Intensity of participants in favor of absence of lack of information exchange is on an average 9 when the number of observations is 20 . It can be increased by increasing information exchange and reducing the standard deviation 1.124 (Figure 1(b)). There is a positive relationship between working experience and stakeholders facing chal- 
lenges due to lack exchange of information. So higher experience can relatively reduce the challenges.

From the box plot diagrams 50th and 75th percent quartile values it can be said that in this case almost all the participants are also very much positive that information exchange is also a crucial factor that is to be dealt aptly in order to integrate the current technologies in monitoring and management of environment. The participants from AUST, BUET, CUET and LGED very strongly recommended this factor as a great challenge (Figure 2(b)). The available information cannot be applied to the practical work as smoothly as the practitioners want. From the histogram and the box plot, it is evident that the majority of the participants are supporting that lack of appropriate and relevant information is another key obstacle against using ML models as decision aided tools.

\subsection{Less Exposure to Research Upshots}

Here the Intensity of participants in favor of absence of less exposure of research upshots is on an average is 8.50, when the number of observations is 20 (Figure $1(c)$ ). So, less exposure of research upshots reduce the intensity. There is a positive relationship between working experience and stakeholders facing challenges due to lack of exposure of research upshots. More experienced person gets more facilities to expose research upshots.

The researches which are conducted on the implementation of ML models are relatively opaque to the majority of the participants who are working at environmental sector, and it is quite evident from the histogram and the box plot diagram (Figure 2(c)). The mean value on the histogram is 8 , and the 75 th percentile value of the box plot diagram is above 8 in maximum cases; hence we can consider it as another key factor. It is crucially important to depict the research upshots explicitly and implicitly both. Because research upshot has got a very positive correlation with funding as well. However, to encapsulate it can be easily said that the assumptions that were made are positively appropriate.

\subsection{Lack of Funding}

The practitioners emphasized difficulties in funding as the 4th key component as per our study which is another negative catalyst against the implementation of ML models for environmental monitoring and management. In case of lower funding standard deviation is higher than other case which is 2.412 (Figure $1(d))$. Intensity of participants facing problems due to difficulties in funding is on an average is 7.65 , so many practitioners fail to take forward steps towards experimentation with ML models. There is a negative relationship between working experience and stakeholders facing challenges due to difficulties in funding. The mean value obtained from the histogram and the upper quartile of the boxplot depicts a value in between 7 to 8 so it was considered the 4th key obstacle. The lowest whisker value is obtained from BUET and the quartile values obtained from BUET illustrates that compared to other participating organiza- 
tions BUET has got less difficulties is managing funding (Figure 2(d)). But the other organizations are facing more problems regarding funding issues as an obstacle.

\subsection{Lack of Interest in Machine Learning}

In order to inculcate the urgency and importance of using up to dated technologies like Machine learning in environmental sector it is very important that the practitioners bear strong interest in that field. While the interview sessions were done along with literature reviews it is evident that interest also plays a crucial role here. The average frequency of the participants in support of augmenting interest in the relevant field is approximately 5.90 and the value of standard deviation from the histogram shows the value as 2.614 (Figure 3(a)). Again from the results obtained from the box plot diagram it can be observed that internal quartiles of each of the participating organizations are at different ranges and so their perception is not fully common. MIST, ICCCAD, CC considers it as a challenge but BUET is comparatively facing less challenge in this field. And the remaining organizations are moderate about this factor (Figure 4(a)).

\subsection{Usage of Old Conventional Techniques}

Traditional engineering or science is also known as sequential engineering or science. In order to complete tasks faster with high accuracy integration of technology is crucial. Sticking to conventional techniques may hinder development process. In this study very renowned organizations and institutes participated

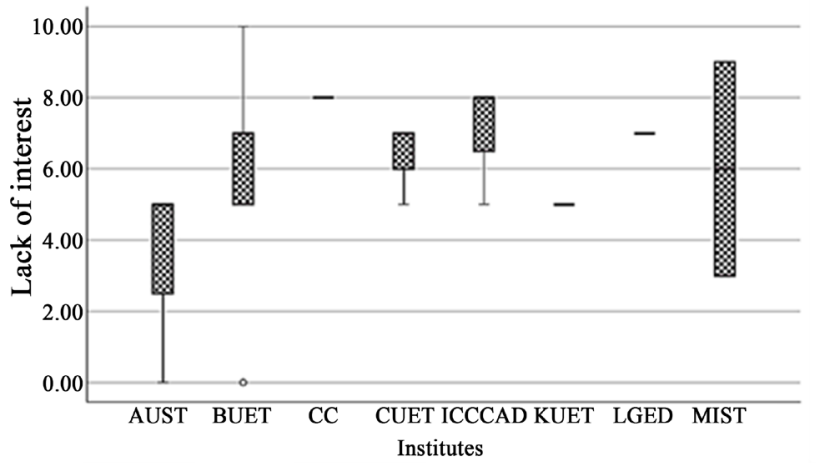

(a)

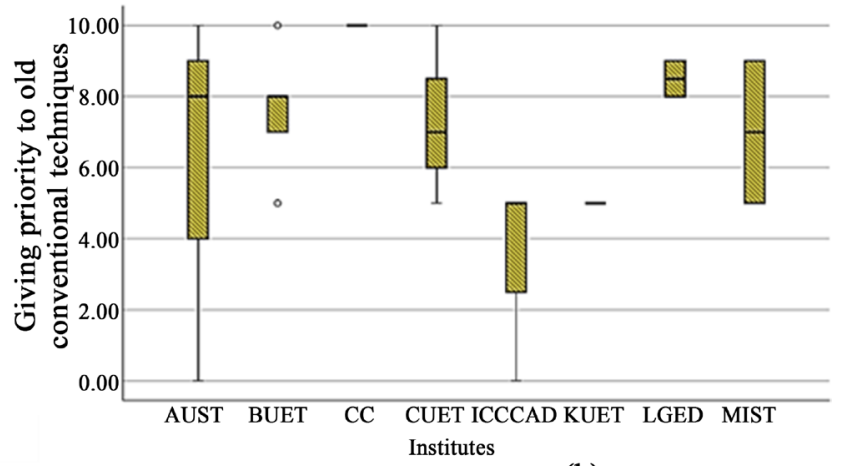

(b)

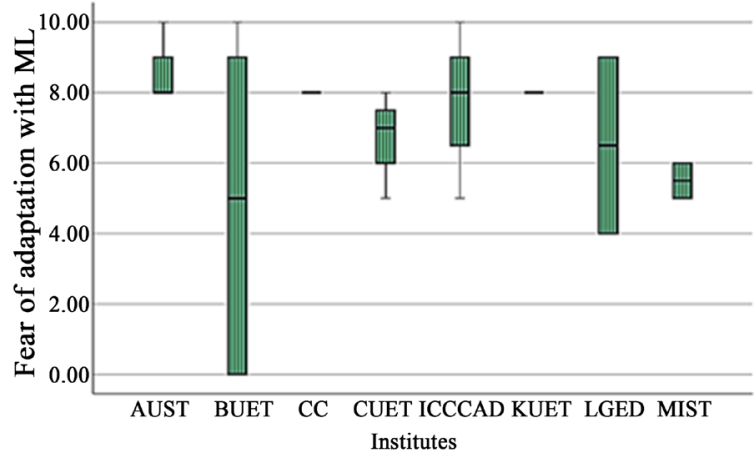

(c)

Figure 3. Perception of respondents on (a) lack of interest; (b) giving priority to old conventional techniques; and (c) fear of adaptation with machine learning. 


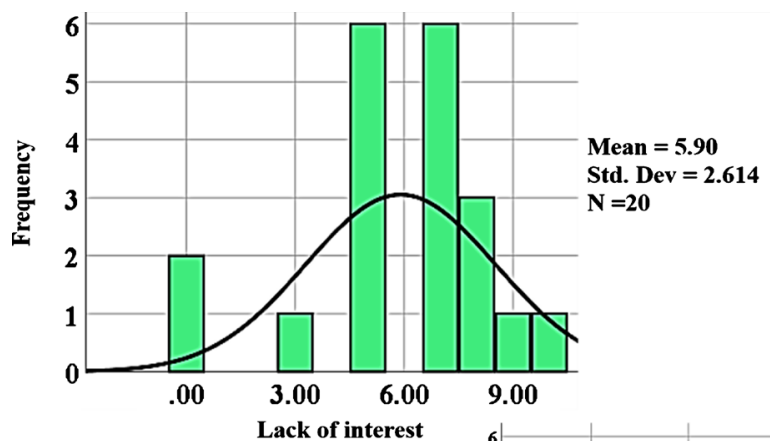

(a)
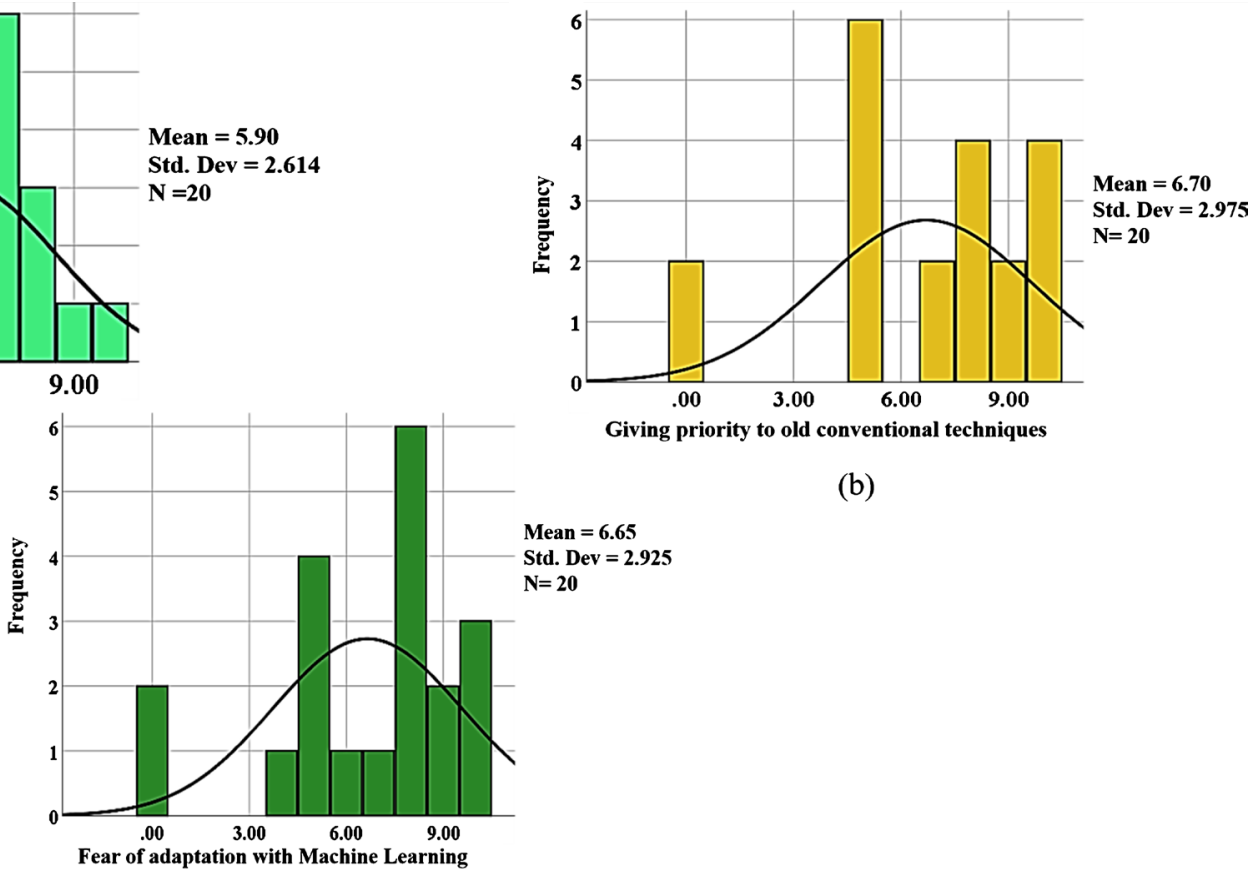

(b)

(c)

Figure 4. Institute wise scoring based on (a) lack of interest; (b) giving priority to old conventional techniques; and (c) fear of adaptation with machine learning.

and also addressed the old conventional techniques as a major challenge as well (Figure 4(b)). The histogram depicts that more than the average number of participants highlighted that giving priority to old conventional techniques may lead to halting of pace and accuracy of analysis (Figure 3(b)). The internal quartiles range depicts that 75 th and 50th percentile values in maximum cases are within range 6 to 8 . Based on the analysis it is evident that old conventional techniques are to be upgraded.

\subsection{Difficulty to Adapt With Machine Learning}

In generic language adaptation is a process of adapting oneself or thing with a new or uncommon work or action. Many find it difficult initially to adapt with a new system. After the literature review was conducted, problems in adaptation with machine learning was identified as a factor that is not allowing practitioners and researchers to indulge themselves in this field effectively. From the histogram diagram the obtained mean value is 6.65 which illustrates that more than $50 \%$ of the participants are supporting and coinciding to this point that fear of adaptation with machine learning is one of the many challenges (Figure 3(c)). Again, the internal quartile ranges of the maximum number of participating organizations and institutes are above 75th percentile with a bit of exception in case of BUET, MIST and LGED (Figure 4(c)).

\section{Conclusion}

In Bangladesh, the integration of ML models can bring a revolutionary change. 
The tools and models can be used to make predictions and monitor various environmental works smoothly in less time and with high accuracy. It will boost the practitioner's performance and bring massive beneficiary results for the students especially at the university level for conducting their research works. ML learning models are not only reliable for high accuracy but also will help to obtain results in short span of time without consuming much time and effort. Also, ML models will assist people to obtain data's and exchange information's globally so that people can work and conduct their research or practical engineering related works remotely and reliably. As technologies are upgrading fast so in Bangladesh if apt measure is taken to solve the aforementioned problems which the stakeholders are facing then it is possible for the people to contribute to Environmental monitoring and management system more aptly both at national and international levels. Due to lack of funding and COVID-19 situation, more intensive work could not possible to do, but more research can be done through conducting face to face interview and stakeholder workshops.

\section{Conflicts of Interest}

The authors declare no conflicts of interest regarding the publication of this paper.

\section{References}

[1] Pyayt, A.L., Mokhov, I.I., Lang, B., Krzhizhanovskaya, V.V. and Meijer, R.J. (2011) Machine Learning Methods for Environmental Monitoring and Flood Protection. World Academy of Science, Engineering and Technology, 78, 118-123.

[2] Tsamardinos, I., Fanourgakis, G.S., Greasidou, E., Klontzas, E., Gkagkas, K. and Froudakis, G.E. (2020) An Automated Machine Learning Architecture for the Accelerated Prediction of Metal-Organic Frameworks Performance in Energy and Environmental Applications. Microporous and Mesoporous Materials, 300, Article ID: 110160. https://doi.org/10.1016/j.micromeso.2020.110160

[3] Thessen, A. (2016) Adoption of Machine Learning Techniques in Ecology and Earth Science. One Ecosystem, 1, e8621. https://doi.org/10.3897/oneeco.1.e8621

[4] Olden, J.D., Joy, M.K. and Death, R.G. (2004) An Accurate Comparison of Methods for Quantifying Variable Importance in Artificial Neural Networks Using Simulated Data. Ecological Modelling, 178, 389-397. https://doi.org/10.1016/j.ecolmodel.2004.03.013

[5] Lund, D., MacGillivray, C., Turner, V. and Morales, M. (2014) Worldwide and Regional Internet of Things (IoT) 2014-2020 Forecast: A Virtuous Circle of Proven Value and Demand. International Data Corporation (IDC), Technical Report, 1, 9.

[6] Hampton, S.E., Jones, M.B., Wasser, L.A., Schildhauer, M.P., Supp, S.R., Brun, J., et al. (2017) Skills and Knowledge for Data-Intensive Environmental Research. BioScience, 67, 546-557. https://doi.org/10.1093/biosci/bix025

[7] Galli, A., Wiedmann, T., Ercin, E., Knoblauch, D., Ewing, B. and Giljum, S. (2012) Integrating Ecological, Carbon and Water Footprint into a 'Footprint Family' of Indicators: Definition and Role in Tracking Human Pressure on the Planet. Ecological Indicators, 16, 100-112. https://doi.org/10.1016/j.ecolind.2011.06.017

[8] Puig, M., Pla, A., Seguí, X. and Darbra, R.M. (2017) Tool for the Identification and 
Implementation of Environmental Indicators in Ports (TEIP). Ocean \& Coastal Management, 140, 34-45. https://doi.org/10.1016/j.ocecoaman.2017.02.017

[9] Porter, J.H., Hanson, P.C. and Lin, C.-C. (2012) Staying Afloat in the Sensor Data Deluge. Trends in Ecology \& Evolution, 27, 121-129.

https://doi.org/10.1016/j.tree.2011.11.009

[10] Villalba, L. and Useche, E. (2021) Methodological Approach for the Construction of Environmental Management Indicators in Universities. Cleaner Environmental Systems, 2, Article ID: 100016. https://doi.org/10.1016/j.cesys.2021.100016

[11] Li, B. and Yao, R. (2009) Urbanisation and Its Impact on Building Energy Consumption and Efficiency in China. Renewable Energy, 34, 1994-1998. https://doi.org/10.1016/j.renene.2009.02.015

[12] Kim, K.J., Yun, W.G., Cho, N. and Ha, J. (2017) Life Cycle Assessment Based Environmental Impact Estimation Model for Pre-Stressed Concrete Beam Bridge in the Early Design Phase. Environmental Impact Assessment Review, 64, 47-56. https://doi.org/10.1016/j.eiar.2017.02.003

[13] Alalouch, C., Al-Saadi, S., AlWaer, H. and Al-Khaled, K. (2019) Energy Saving Potential for Residential Buildings in Hot Climates: The Case of Oman. Sustain. Sustainable Cities and Society, 46, Article ID: 101442. https://doi.org/10.1016/j.scs.2019.101442

[14] Hipsey, M.R., Hamilton, D.P., Hanson, P.C., Carey, C.C., Coletti, J.Z., Read, J.S., et al. (2015) Predicting the Resilience and Recovery of Aquatic Systems: A Framework for Model Evolution within Environmental Observatories. Water Resources Research, 51, 7023-7043. https://doi.org/10.1002/2015WR017175

[15] Farley, S.S., Dawson, A., Goring, S.J. and Williams, J.W. (2018) Situating Ecology as a Big-Data Science: Current Advances, Challenges, and Solutions. BioScience, 68, 563-576. https://doi.org/10.1093/biosci/biy068

[16] Donoho, D. (2017) 50 Years of Data Science. Journal of Computational and Graphical Statistics, 26, 745-766. https://doi.org/10.1080/10618600.2017.1384734

[17] Hampton, S.E., Strasser, C.A., Tewksbury, J.J., Gram, W.K., Budden, A.E., Batcheller, A.L., et al. (2013) Big Data and the Future of Ecology. Frontiers in Ecology and the Environment, 11, 156-162. https://doi.org/10.1890/120103

[18] Grasso, D. (2019) Evolving Environmental Engineering for the 21st Century. Environmental Science \& Technology, 53, 7183-7184.

https://doi.org/10.1021/acs.est.9b03244

[19] Water Environment Federation (2018) Harnessing Artificial Intelligence for the Earth. Water Environment Federation, Geneva.

[20] Nazir, U., Mian, U.K., Sohail, M.U., Taj, M. and Uppal, M. (2020) Kiln-Net: A Gated Neural Network for Detection of Brick Kilns in South Asia. IEEE Journal of Selected Topics in Applied Earth Observations and Remote Sensing, 13, 3251-3262. https://doi.org/10.1109/JSTARS.2020.3001980

[21] Wu, D., Lary, D.J., Zewdie, G.K. and Liu, X. (2019) Using Machine Learning to Understand the Temporal Morphology of the $\mathrm{PM}_{2.5}$ Annual Cycle in East Asia. Environmental Monitoring and Assessment, 191, Article No. 272. https://doi.org/10.1007/s10661-019-7424-1

[22] Gumma, M.K., Thenkabail, P.S., Teluguntla, P.G., Oliphant, A., Xiong, J., Giri, C., et al. (2020) Agricultural Cropland Extent and Areas of South Asia Derived Using Landsat Satellite 30-m Time-Series Big-Data Using Random Forest Machine Learning Algorithms on the Google Earth Engine Cloud. GIScience \& Remote Sensing, 57, 302-322. https://doi.org/10.1080/15481603.2019.1690780 
[23] Ganguly, K.K., Nahar, N. and Hossain, B.M. (2019) A Machine Learning-Based Prediction and Analysis of Flood Affected Households: A Case Study of Floods in Bangladesh. International Journal of Disaster Risk Reduction, 34, 283-294. https://doi.org/10.1016/j.ijdrr.2018.12.002

[24] Al Kafy, A., Al-Faisal, A., Rahman, S., Islam, M., Al Rakib, A., Khan, H.H., et al. (2021) Prediction of Seasonal Urban Thermal Field Variance Index Using Machine Learning Algorithms in Cumilla, Bangladesh. Sustainable Cities and Society, 64, Article ID: 102542. https://doi.org/10.1016/j.scs.2020.102542

[25] Stachl, C., Pargent, F., Hilbert, S., Harari, G.M., Schoedel, R., Vaid, S., et al. (2020) Personality Research and Assessment in the Era of Machine Learning. European Journal of Personality, 34, 613-631. https://doi.org/10.1002\%2Fper.2257 